\title{
O QUE HÁ DE NOVO NAS DISPUTAS CURRICULARES?*
}

\author{
ANDRÉ PiCANÇO FAVACHO**
}

A

concepção de currículo como campo de disputa não é nova, pois veio à tona, internacionalmente, nos anos de 1970 e, no Brasil, nos anos de 1980. Revelou-se, desde então, um importante balizador para a análise das relações de poder que envolvem os currículos. O próprio professor Miguel Arroyo contribuiu fortemente para o debate dessa época.

Se o referido tema não é novo, qual é o acréscimo que traz o último livro de Arroyo, Currículo, território em disputa? O autor destaca que o currículo não é apenas território de disputas teóricas. Quem disputa vez nos currículos são os sujeitos da ação educativa: os docentes-educadores e os alunos-educandos. Os professores e alunos não se pensam apenas como ensinantes e aprendizes dos conhecimentos dos currículos, mas exigem ser reconhecidos como sujeitos de experiências sociais e de saberes que requerem ter vez no território dos currículos.

Arroyo aponta ainda duas novidades: 1) o currículo oficial está cada vez mais pressionado pelos coletivos populares, que exigem o direito de ver suas narrativas também pronunciadas pela escola; 2) entretanto, esses coletivos, por sua vez, não lutam mais pela escolarização em si; aos poucos passaram a entender que o processo de sua afirmação como sujeitos de direitos não se dá exclusivamente pela escola (promessa apregoada por muito tempo). Agora, a luta é por pertencimento social amplo, por acesso aos bens materiais e culturais, simbólicos e memoriais, na diversidade de espaços sociais, onde o direito à escola adquire outra relevância. Assim, os coletivos populares, embalados por um amplo movimento de afirmação, inverteram a antiga lógica: articulam o seu direito à escola à conquista e ocupação de outros espaços e, com isso, pressionam o currículo oficial para incorporar o resultado de suas lutas.

\footnotetext{
* $\quad$ Resenha do livro Currículo, território em disputa, de Miguel Arroyo (Petrópolis: vozes, 2011. 374p.).

* $\quad$ Doutor em Educação e professor da Faculdade de Educação da Universidade Federal de Minas Gerais (UFMG). E-mail: afavacho@uol.com.br
} 
Isso não significa que o currículo oficial perdeu sua força controladora, mas sim que algo realmente forte inaugurou-se: a possibilidade de que as histórias-memórias dos diversos sujeitos sejam contadas, ainda que por meio de outras linguagens. Assim, não se trata de uma vitória final dos coletivos populares sobre o Estado, mas de uma nova estratégia de luta que tem alterado o lugar da escolarização na visão desses coletivos, e também na visão da academia, que vendia a ideia de que a escolarização retiraria os brasileiros da subcidadania. Também não se trata de uma prática completamente difundida e consolidada entre os professores, mas apenas de um desenho alternativo de currículo onde os saberes da docência tenham vez.

Obviamente, a escola continua importante para esses sujeitos, mas os saberes, as conquistas, as experiências e tudo mais que as novas lutas são capazes de produzir podem, estrategicamente, se converter em prática curricular, em conteúdo político, em ato a ser valorizado dentro da escola. Tal situação tem ameaçado fortemente o currículo oficial, uma vez que se vê brotar no seu interior algo maior que ele mesmo: a inesperada ação dos movimentos sociais que adentra os processos de escolarização por outra via: a do acesso pelo direito. Isso justifica a forte reação estatal: Parâmetros Curriculares Nacionais, Provinha Brasil, Exame Nacional do Ensino Médio (Enem), Diretrizes Curriculares Nacionais, Índice de Desenvolvimento da Educação Básica (Ideb), entre outros; tudo com o intuito de reforçar o caráter conteudista e cognitivista da escolarização, bem como retirar o poder da nova estratégia, essa que une saberes, direito e escolarização.

Para ilustrar as questões apresentadas até aqui, me remeto, parte a parte, ao livro de Arroyo.

Na primeira parte, intitulada "Os professores e seus direitos a ter vez nos currículos - autorias, identidades profissionais", Arroyo acredita que a atividade do professor não se reduz, de forma alguma, a validar o controle das instâncias superiores sobre a escola. Entretanto, essas instâncias tiveram o poder de bloquear a arte de educar dos professores, isto é, de governar o campo das possibilidades de se ensinar de outras maneiras, com práticas inventadas, criadas e imaginadas pelos professores, ou seja, bloquearam a autoria profissional do professor e seus saberes docentes. Para o autor, dois grandes momentos históricos foram responsáveis, no Brasil, por esse bloqueio: a ditadura de 1964 e as atuais políticas neoliberais; ambas produziram a secundarização da autoria docente, substituindo-a por controles de mercado e controles científicos, com o intuito de matematizar e estatistizar os resultados escolares através de modelos de competências, reduzidos ao treinamento e fórmulas descontextualizadas de metas avaliativas. Contudo, para Arroyo, a autoria docente não foi totalmente eliminada, uma vez que a arte de educar não se separa do mundo da vida, das práticas reais das pessoas, de suas mazelas, de seus desejos. Embora alguns queiram negar essa relação, não se pode desconsiderar que são os 
eventos sociais, culturais e políticos que convocam a docência para a ação. E é isso que desbloqueia a arte de educar ou a autoria docente.

A segunda parte do livro, "Os saberes do trabalho docente disputam lugar nos currículos", denuncia que, lamentavelmente, contra os avanços de se educar partindo das vivências humanas ou desumanas dos sujeitos, vê-se nascer, nos dias de hoje, financiada pelas reformas educacionais, a função aulista do professor. Tal fato substitui a necessária função educadora da docência - que é a própria arte de educar - pelo frio cumprimento de metas do ensino por competência e de avaliação de resultados. Isso ocorre porque as políticas públicas da educação entendem que os saberes daqueles que frequentam a escola pública são desqualificados, sem crédito, sem valor; são saberes pobres, de pobres; pretendem educar os alunos para a empregabilidade, para esse tipo de trabalho que mais desumaniza do que humaniza. Para Arroyo, infelizmente, perdemos a possibilidade de substituir esse trabalho embrutecido e embrutecedor por um trabalho cujo princípio é a transformação do homem para que ele se integre à vida, ao mundo, enfim, às práticas sociais; perdemos a oportunidade de educar a partir do trabalho cujo princípio é educativo. $\mathrm{O}$ trabalho como princípio educativo é, para Arroyo, o elo perdido dos saberes docentes, mas também o elo a ser encontrado.

Na terceira parte do livro, Arroyo defende a tese de que "Os sujeitos sociais e suas experiências se afirmam no território do conhecimento", isto é, apesar de haver o impedimento às experiências sociais para se integrarem ao conhecimento considerado legítimo, os coletivos sociais mostram que os saberes têm, sim, sua origem na experiência social e não apenas na artificialidade das questões epistemológicas. Se isso for negado ou ignorado, produziremos, além de injustiça social, uma injustiça cognitiva, diz Arroyo, citando Zygmunt Baumn. Manter essa separação entre experiência social e conhecimento legítimo é sustentar a brutal hierarquização dos saberes, é desperdiçar experiências sociais, é desconsiderar que todo conhecimento tem sua origem na experiência social; é, enfim, empobrecer os currículos pela negação das experiências sociais e da sua diversidade.

Na quarta parte do livro, "As crianças, os adolescentes e os jovens abrem espaços nos currículos", o autor apresenta duas questões potentes para esse debate. A primeira é que a pedagogia, a partir das novas vivências das crianças e jovens, foi interrogada na sua visão messiânica, romântica de criança e promotora de destinos, dando lugar a outra pedagogia capaz de (1) revelar às crianças-adolescentes suas próprias configurações na realidade, uma vez que hoje se torna cada vez mais difícil separar infância de adolescência, cabendo à pedagogia se interessar por esse "hífen" que não separa, mas une; (2) traduzir o perverso e tenso real vivido por essas infâncias, posto que elas não mais acreditam nas antigas ilusões que a pedagogia, por vezes, ainda tenta sustentar; (3) revelar às crianças-adolescentes seus direitos negados. 
A segunda questão reside no embate entre as concepções inovadoras e as concepções conservadoras para a educação da infância e adolescência. Vê-se nascerem propostas cada vez mais propedêuticas, sequenciais, lineares e etapistas, enfim, propostas pobres de experiências, competindo com propostas ávidas por revelar o humano nomeado através da palavra, o que, em termos educacionais e benjaminianos, poderia ajudar a criança a saber mais de si, nomear-se, revelar-se e revelar o outro. No que concerne especificamente aos jovens, eles já sabem, e não se deixam mais enganar que serão incluídos socialmente por meio da escolarização. Já sabem que, para que essa velha promessa possa se efetivar, o lugar-escola, os tempos, os espaços, a organização e a estrutura escolar deveriam se alterar e nada se alterou. Sabem que são vistos como Outros "in-incluíveis", ou seja, aqueles que não sabem reconhecer os esforços do poder público para a melhoria de sua educação. Mas, quais são mesmo os esforços? Os jovens resistem a conviver em um sem-lugar, isto é, resistem a habitar em um espaço que, em qualquer momento, foi para eles pensado.

Na quinta e última parte do livro, Arroyo se ocupa com "O direito a conhecimentos emergentes nos currículos". Indigna-se com o fato de que as crianças-adolescentes "passarão anos na educação fundamental, complementarão a educação média e sairão sem saber nada ou pouco de si mesmos" (p. 262). Arroyo preconiza que saber de si é reconhecer-se vivo numa temporalidade, espacialidade e memorialidade específicas. Pode ser, também, saber-se sem-lugar e reivindicar valorizado o que foi tomado como desvalor; não apenas para ter o reconhecimento do outro, mas para ter o direito de contar a própria história, a exemplo dos coletivos afrodescendentes, indígenas e quilombolas. Pode ser, ainda, a capacidade pedagógica dos docentes de escutarem esse saber de si, auxiliando esses coletivos com novas propostas pedagógicas. Um exemplo: o tempo dos coletivos marginalizados não é o mesmo tempo da escola; o tempo deles é o aqui e agora, enquanto o da escola é o futuro. Não seria o caso de a escola praticar o tempo presente, que não é um nem outro tempo, mas o reconhecimento de como outras identidades foram parar no esquecimento, propondo que esses coletivos libertem seus saberes da condição folclórica a que foram submetidos? O que está em jogo na luta pelo saber de si mesmo é (des)romantizar a pedagogia e, portanto, os sujeitos da pedagogia: professores e alunos; acordá-los desse sono durante o qual se acredita, erroneamente, que cada um nasceu para o que é.

Para finalizar, é bom lembrar que o livro de Arroyo é rico em exemplos de didáticas de reconhecimento de sujeitos, isto é, de didáticas mais radicais e mais significativas para a docência de hoje.

Desejo a todos uma ótima leitura e que cada um possa apreciar os escritos de Arroyo a sua maneira. 